Tropical Journal of Pharmaceutical Research June 2017; 16 (6): 1357-1363

ISSN: $1596-5996$ (print); 1596-9827 (electronic)

(C) Pharmacotherapy Group, Faculty of Pharmacy, University of Benin, Benin City, 300001 Nigeria.

All rights reserved.

Available online at http://www.tjpr.org

Original Research Article

http://dx.doi.org/10.4314/tjpr.v16i6.20

\title{
Pre-cold stress increases acid stress resistance and induces amino acid homeostasis in Lactococcus lactis NZ9000
}

\author{
Taher Khakpour Moghaddam ${ }^{1,2}$, Juan Zhang ${ }^{1,2}$, Guocheng Du ${ }^{1,2 *}$ \\ ${ }^{1}$ Key Laboratory of Industrial Biotechnology, Ministry of Education, ${ }^{2}$ School of Biotechnology, Jiangnan University, Wuxi, \\ Jiangsu 214122, People's Republic of China \\ *For correspondence: Email: gcdu@jiangnan.edu.cn
}

Sent for review: 27 January 2017

Revised accepted: 12 May 2017

\begin{abstract}
Purpose: To investigate the effects of pre-cold stress treatments on subsequent acid stress resistance and the viability of Lactococcus lactis during acid fermentation.

Methods: Bacterial strains were grown at $4^{\circ} \mathrm{C}$ for $2 \mathrm{~h}$ pre-adaptation, and then subjected to various stresses including exposure to $4{ }^{\circ} \mathrm{C}, 1 \mathrm{mM}$ hydrogen peroxide, $5 \%$ sodium chloride, $7 \%$ ethanol, and lactic acid (pH 5.5) to determine if any of these stress treatments could increase acid stress resistance and induce amino acid homeostasis during acid fermentation.

Results: Among the different abiotic stresses investigated, pre-adaptation of lag-phase cultures to cold shock significantly enhanced cell survival during subsequent acid stress. The stress profile of $L$. lactis pre-adapted to cold stress revealed induction of amino acid homeostasis and energy balance; however, pre-adaptation responses are induced upon exposure to acid stress alone. Compared to exposure to acid stress only, pre-adaptation to cold stress decreased the redox balance ratio and the formation of hydroxyl radicals, indicating a change in aerobic respiration and oxidative state of the bacteria.

Conclusion: Pre-adaptation to cold stress rescued L. lactis from the deleterious effects of subsequent acid exposure by modifying the amino acid metabolic pathway, leading to an improvement in redox mobility of acid stress response.
\end{abstract}

Keywords: Pre-cold stress, Acis stress resistance, Lactococcus lactis, Redox balance, Amino acid homeostasis

Tropical Journal of Pharmaceutical Research is indexed by Science Citation Index (SciSearch), Scopus, International Pharmaceutical Abstract, Chemical Abstracts, Embase, Index Copernicus, EBSCO, African Index Medicus, JournalSeek, Journal Citation Reports/Science Edition, Directory of Open Access Journals (DOAJ), African Journal Online, Bioline International, Open-J-Gate and Pharmacy Abstracts

\section{INTRODUCTION}

Lactic acid bacteria (LAB) are of great importance in the biotechnology and food industry. Lactococcus lactis has long been used as a starter to improve the stability of silages under aerobic conditions by acidifying the substrate, thereby reducing yeast and mould growth [1]. The development of new functional foods containing bioactive compounds such as probiotics and prebiotics is of great interest to the food industry and regulatory authorities, because in addition to their basic nutritional benefits, they have a significant impact on human health [2]. Therefore, LAB preservation is needed to obtain concentrated viable starters with stress tolerance. Several studies have demonstrated that during fermentation, decreased $\mathrm{pH}$ leads to bacterial cell damage and thus decreased viability [3]. However, because $L$. lactis grow in anaerobic environments, fermenting glucose differs in metabolism and production [4] and viability and metabolic activity during 
fermentation are affected by stressful conditions $[1,5]$.

Several studies have shown that exposing bacteria to moderate stress activates functional and structural mechanisms that enhance their physiological resistance to subsequent stress [6]. $L A B$ are exposed to various types of stress during the fermentation process such as low temperature [7], high hydrogen peroxide $\left(\mathrm{H}_{2} \mathrm{O}_{2}\right)$ [8] and salt ( $\mathrm{NaCl})$ [4] levels, and low pH [9]. In virulent $L$. lactis strains, it has been demonstrated that pre-adaptation to sub-lethal acid conditions minimises the lethal effects of subsequent extreme-acid conditions by inducing the activation of amino acid metabolic pathways associated with intracellular $\mathrm{pH}$ homeostasis, resulting in enhancement of the acid tolerance response (ATR) system [10]. The association among various stressful conditions such as low temperature and low $\mathrm{pH}$, physiological responses such as cell growth, and biochemical modifications such as the amino acid profile [6] and redox balance can be analysed by metabolic approaches. Improvements in the efficiency of technological processes to develop new functional food processes are increasingly required. Therefore, its is necessary to determine the pre-adaptation properties of salt, cold, acid, oxygen, and ethanol on the L. lactis NZ9000 redox system balance, amino acid profile, and acid stress tolerance [3]. Changes in the ability of the ATR to protect $L$. lactis from various stressors have been determined by investigating how changes in amino acid metabolism during fermentation lead to altered bacterial metabolism and physiological function [1]. In this study, to evaluate the protective effects of pre-stress on bacterial growth and viability, cell recovery after exposure to various types of stressors at different $\mathrm{pH}$ was assessed through determination of amino acid homeostasis and redox mobility.

\section{EXPERIMENTAL}

\section{Bacterial strains and growth conditions}

L. lactis ssp. cremoris NZ9000 was obtained from Professor Jian Chen (Key Laboratory of Industrial Biotechnology, Jiangnan University, Wuxi, China). The bacterial strain was grown statically at $30^{\circ} \mathrm{C}$ without aeration in $\mathrm{M} 17$ broth (Oxoid, Basingstoke, UK) supplemented with 5 $\mathrm{g} / \mathrm{L}$ glucose, unless otherwise stated.

\section{Stress treatments}

Log-phase cell cultures were centrifuged at $5400 \times \mathrm{g}$ for $7 \mathrm{~min}$, and the resulting cell pellet was re-suspended in an equal volume of GM17 medium. The cells were subjected to five types of stress: cold stress $\left(4^{\circ} \mathrm{C}\right)$, oxidative stress $(1 \mathrm{mM}$ $\mathrm{H}_{2} \mathrm{O}_{2}$ ), osmotic stress $(5 \% \mathrm{NaCl})$, alcohol stress (7\% ethanol), and acid stress (pH 5.5 lactic acid). These conditions are within the range of conditions typically encountered by bacteria during food processing. For this study, these stressors were applied during a $2 \mathrm{~h}$ preadaptation phase (shock) and then adjusted with lactic acid ( $\mathrm{pH} \mathrm{4.0)}$ for $6 \mathrm{~h}$ (acid stress). Nonstressed strains cultured in GM17 served as positive controls. Serial 10 -fold dilutions of preand post-stress culture samples were plated to estimate the number of colony-forming units. At the end of the shock and stress treatments, the cultures were divided into two samples and centrifuged at $5400 \times \mathrm{g}$ for $7 \mathrm{~min}$. The first sample was subjected to further acid stress at $\mathrm{pH} 5.5$, 4.5 , and 3.5 and incubated at $30^{\circ} \mathrm{C}$ for $6 \mathrm{~h}$. The second sample served as the assay control.

\section{Quantification of the nicotinamide nucleotide ratio}

The nicotinamide nucleotide ratio $\left(\mathrm{NAD}^{+} / \mathrm{NADH}\right)$ was determined using the BioVision NAD $/ \mathrm{NADH}$ Quantification Kit (Research Products, Milpitas, CA, USA) according to the manufacturer's instructions. Bacterial suspensions were centrifuged at $6000 \times \mathrm{g}$ for $7 \mathrm{~min}$. The pellets were washed twice with cold sterile phosphatebuffered saline (PBS, pH 7.2), centrifuged at $8000 \times \mathrm{g}$ for $3 \mathrm{~min}$, and lysed using $334 \mathrm{\mu g}$ microbeads (106 $\mu \mathrm{m}$ in diameter) in a MiniBeadbeater (Sigma, St. Louis, MO, USA). Samples were centrifuged at $14,000 \times \mathrm{g}$ for $5 \mathrm{~min}$ to obtain clear supernatant. The protein concentration of the supernatant was determined [11] and the $\mathrm{NAD}^{+} / \mathrm{NADH}$ measurements were normalised to protein quantity.

\section{Hydroxyl radical measurement}

Hydroxyl radical $(\mathrm{OH} \cdot)$ levels were measured using hydroxyphenyl fluorescein (HPF) as previously described [12]. Bacterial cultures were centrifuged at $8400 \times \mathrm{g}$ for $4 \mathrm{~min}$ at $4^{\circ} \mathrm{C}$, washed twice with an equal volume of sterile PBS, and centrifuged at $8000 \times \mathrm{g}$ for $3 \mathrm{~min}$. Positive control bacteria were treated with $\mathrm{H}_{2} \mathrm{O}_{2}(25 \mathrm{mM})$ and negative control bacteria were untreated. For the measurements, all of the samples were first diluted to a concentration of 106 bacteria $/ \mathrm{mL}$, after which HPF was added to a final concentration of $10 \mu \mathrm{M}$ per reaction mixture [13]. The solutions were incubated at $20^{\circ} \mathrm{C}$ for $75 \mathrm{~min}$ in the dark. Fluorescence was measured using a DTX 880 multimode detector (Beckman Coulter, Brea, CA, USA) at an excitation wavelength of $460 \mathrm{~nm}$ and an emission wavelength of $520 \mathrm{~nm}$. 


\section{Determination of intracellular amino acid content}

Bacterial cells were grown to mid-log phase in GM17 culture medium for a $2 \mathrm{~h}$ pre-cold stress treatment at $4^{\circ} \mathrm{C}$, followed by stress treatment. The cells were collected by centrifugation at $8000 \times \mathrm{g}$ for $8 \mathrm{~min}$ and then washed twice in sterile distilled water. The collected cells were suspended in $0.5 \mathrm{~N}$ perchloric acid and disrupted with glass beads. The homogenate was kept on ice for $15 \mathrm{~min}$ and centrifuged to obtain the supernatant. The $\mathrm{pH}$ of the supernatant was adjusted to 2.0 using lithium hydroxide and then kept on ice for $15 \mathrm{~min}$. The sample was centrifuged to remove the precipitate. The concentration of free amino acids was quantified using a Hitachi L-8900 amino acid analyser (Hitachi, Tokyo).

\section{Statistical analysis}

Data were subjected to statistical analysis (Student's $t$-test) using SPSS software version 16.0 (SPSS, Chicago, IL, USA). The data are expressed as mean \pm standard deviation (SD) and $p<0.05$ was considered statistically significant.

\section{RESULTS}

\section{Stress tolerance and survival rate of $L$. lactis subjected to multiple stressors}

The response of $L$. lactis to $8 \mathrm{~h}$ of acid-, cold-, osmotic-, peroxide- and ethanol-induced stress is presented in Figure 1. Acid, cold, and osmotic stress significantly decreased $L$. lactis survival. As shown in Figure 1, L. lactis treated with cold, lactic acid and salt conditions for $8 \mathrm{~h}$ had higher survival rates than control bacteria.

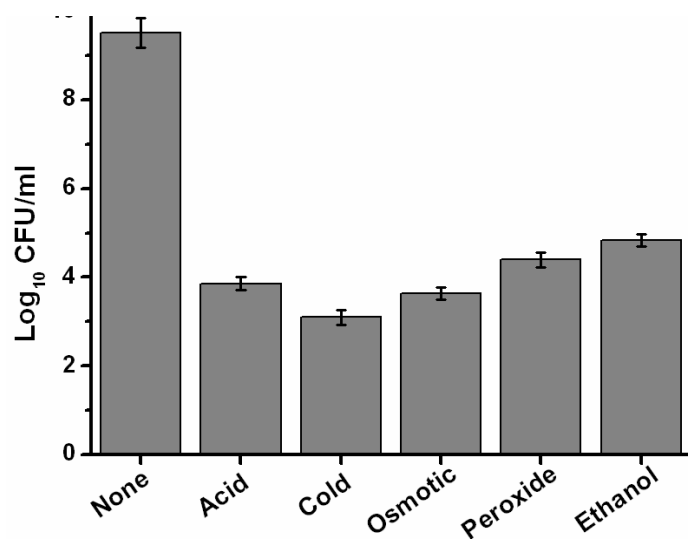

Figure 1: Survival rate of $L$. lactis after stress treatments. Survival rate of $L$. lactis after no stress (none) and lactic acid pH 5.5 (acid), $4{ }^{\circ} \mathrm{C}$ (cold), $5 \%$ $\mathrm{NaCl}$ (osmotic), $1 \mathrm{mM} \mathrm{H}_{2} \mathrm{O}_{2}$ (peroxide) and $7 \%$ ethanol stress for $8 \mathrm{~h},(n=3)$
Stress tolerance and survival rate of L. lactis subjected to various pre-stressors and subsequent acid stress

Pre-adaptation to acid, cold, and osmotic shock significantly reduced cell survival during subsequent acid stress exposure (Figure 2). Conversely, pre-adaptation of L. lactis to cold (4 $\left.{ }^{\circ} \mathrm{C}\right)$, osmotic (5\% NaCl), and acid ( $\left.\mathrm{pH} 5.5\right)$ shock resulted in a significant increase in survival following acid stress compared to the control. Pre-stress conditions followed by acid stress $(\mathrm{pH}$ 4.0) decreased the stress tolerance of L. lactis relative to those subjected to acid stress alone. In addition, pre-cold $\left(4^{\circ} \mathrm{C}\right)$, lactic acid ( $\left.\mathrm{pH} 5.5\right)$, and salt $(5 \% \mathrm{NaCl})$ stress significantly increased the cell survival rate (Figure 2). Significant differences in cell biomass were observed between pre-cold stress shock cultures and subsequent acid stress cultures.

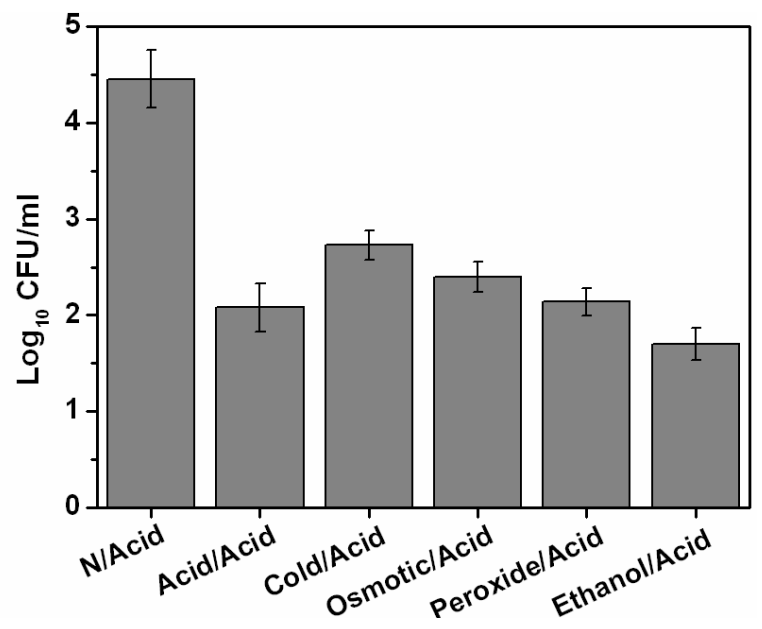

Figure 2: Survival rate after shock and subsequent stress treatment. Survival of $L$. lactis after preadaptation to no stress (N), lactic acid pH 5.5 (acid), 4 ${ }^{\circ} \mathrm{C}$ (cold), $5 \% \mathrm{NaCl}$ (osmotic), $1 \mathrm{mM} \mathrm{H}_{2} \mathrm{O}_{2}$ (peroxide) and $7 \%$ ethanol stress for $2 \mathrm{~h}$ and then exposure to $\mathrm{pH} 4.0$ acid stress for $6 \mathrm{~h}(\mathrm{n}=3)$

\section{Oxidative performance}

Pre-adaptation to cold or osmotic stress alone significantly decreased the ratio of $\mathrm{NAD}^{+} / \mathrm{NADH}$, while exposure to acid stress changed this ratio compared to that of the controls. When L. lactis was pre-adapted to cold or osmotic stress and subsequently exposed to acid stress, a significant decrease in the $\mathrm{NAD}^{+} / \mathrm{NADH}$ ratio was observed compared to bacterial cultures with no initial stress but subsequent acid stress (Figure 3).

The production of $\mathrm{OH}$. led to a significant decrease in the pre-adaptation capacity of the bacteria to cold and osmotic stress. Exposure to 


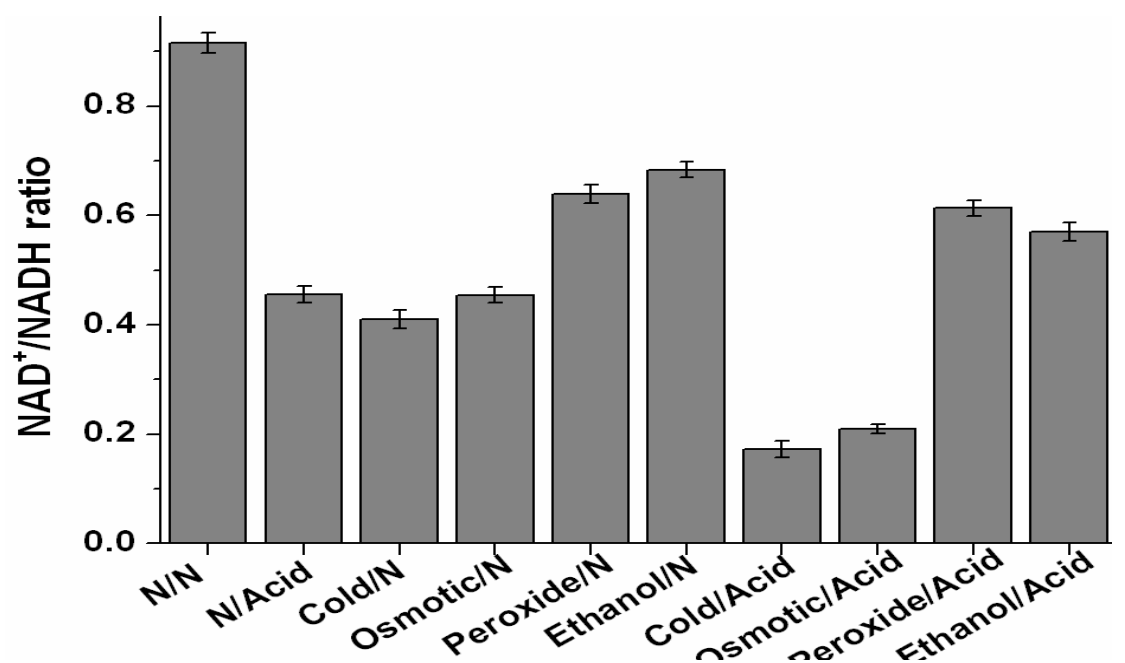

Figure 3: $\mathrm{NAD}^{+} / \mathrm{NADH}$ ratio in $L$. lactis after $2 \mathrm{~h}$ pre-stress treatments and subsequent exposure to no stress $(\mathrm{N})$ or $\mathrm{pH} 4.0$ lactic acid stress (acid) for $6 \mathrm{~h}(\mathrm{n}=3)$

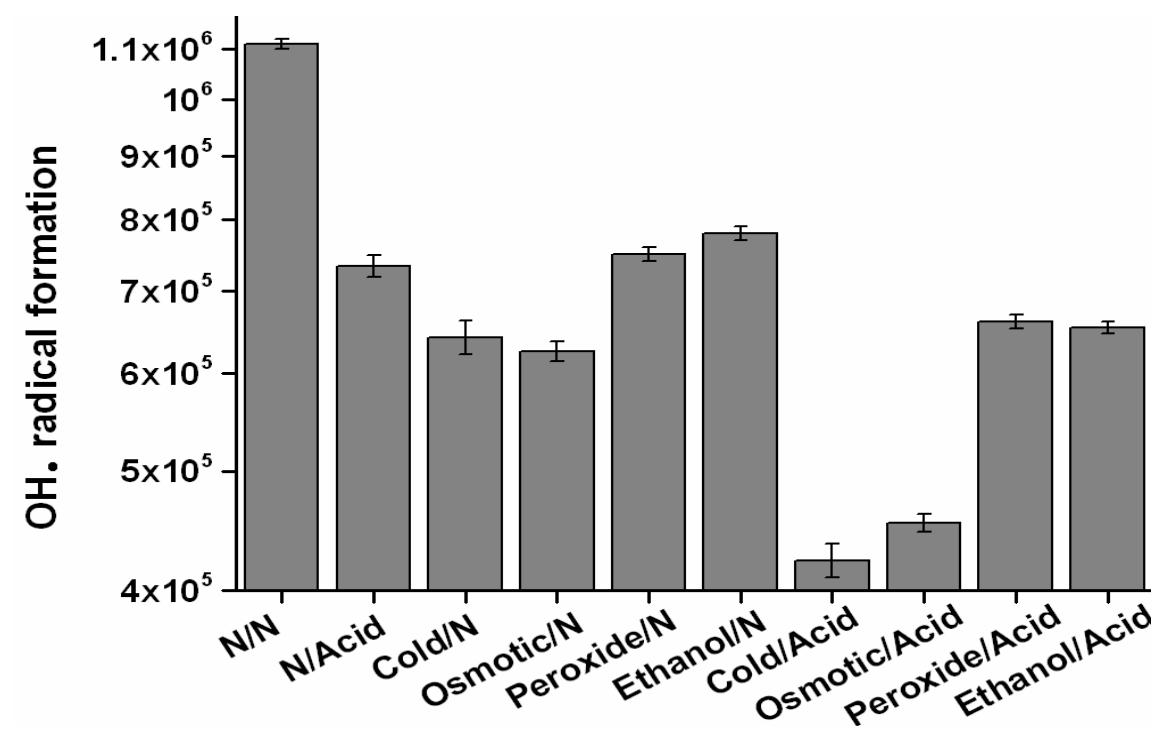

Figure 4: $\mathrm{OH} \cdot$ radical ratio in $L$. lactis after $2 \mathrm{~h}$ pre-stress treatments and subsequent exposure to no stress $(\mathrm{N})$ or $\mathrm{pH} 4.0$ lactic acid stress (acid) for $6 \mathrm{~h}(\mathrm{n}=3)$

no initial stress and subsequent acid stress significantly changed the amount of $\mathrm{OH}$. produced. When $L$. lactis was pre-adapted to cold or osmotic stress and subsequently exposed to acid stress, $\mathrm{OH}$ - production further declined (Figure 4). This indicated that pre-adaptation to cold or osmotic stress induced multiple metabolic cascades that relieved the redox damage caused by acid stress. In addition, these results suggest that oxidative activities in the electron transport chain (ETC) are possible mechanisms for acid adaptation and tolerance in $L$. lactis.

\section{Intracellular amino acid abundance}

The amount of intracellular amino acids markedly increased after pre-adaptation to cold stress and subsequent acid stress exposure (Table 1). At $\mathrm{pH} 3.5$, the intracellular amount of cysteine, phenylalanine, glutamine, aspartate, and threonine was enhanced by 4.12-, 4.01-, 3.34-, 3.11 - and 3.01-fold, respectively, relative to the control at pH 3.5, while the amount of proline and methionine was reduced. These results showed that pre-cold stress altered the intracellular amino acid content in a pH-dependent manner. Furthermore, pre-cold stress played an important role in intracellular amino acid homeostasis, an adaptive response to lactic acid stress during fermentation.

\section{DISCUSSION}

The effects of pre-cold stress on L. lactis NZ9000 resistance to acid stress were evaluated. Preadaptation of $L$. lactis to cold stress (storage at 4 ${ }^{\circ} \mathrm{C}$ for $2 \mathrm{~h}$ ) significantly increased cell viability during subsequent exposure to $\mathrm{pH} 3.5$ acid 
Table 1: Amount (nmol/mg protein) of intracellular amino acids in L. lactis. Cells were pre-adapted to cold stress $\left(4^{\circ} \mathrm{C}\right.$ for $2 \mathrm{~h}$ ) and then were exposed to $\mathrm{pH}$ stress treatments for $6 \mathrm{~h}$

\begin{tabular}{|c|c|c|c|c|c|c|}
\hline \multirow{2}{*}{$\begin{array}{l}\text { pH } \\
\text { condition }\end{array}$} & \multicolumn{2}{|c|}{ pH 5.5} & \multicolumn{2}{|c|}{ pH 4.5} & \multicolumn{2}{|c|}{ pH 3.5} \\
\hline & -Pre-cold & +Pre-cold & -Pre-cold & +Pre-cold & -Pre-cold & +Pre-cold \\
\hline Asp & 882.4 & 898.8 & 372.2 & 451.1 & 76.6 & 238.5 \\
\hline Thr & 606.1 & 611.4 & 191.4 & 266.1 & 45.0 & 135.7 \\
\hline Ser & 539.2 & 569.9 & 193.8 & 287.2 & 106.8 & 189.2 \\
\hline Asp $\mathrm{NH}_{2}$ & 207.8 & 221.0 & 68.2 & 79.2 & 98.5 & 120.2 \\
\hline Glu & 4317.4 & 4330.8 & 2011.1 & 2576.2 & 283.9 & 948.3 \\
\hline Glu $\mathrm{NH}_{2}$ & 990.2 & 1010.1 & 101.4 & 111.3 & 143.4 & 210.9 \\
\hline Gly & 881.4 & 901.1 & 471.5 & 511.4 & 79.1 & 156.0 \\
\hline Ala & 992.2 & 998.3 & 453.9 & 543.6 & 82.2 & 165.4 \\
\hline Val & 309.1 & 311.2 & 93.8 & 101.0 & 52.5 & 94.1 \\
\hline Met & 102.4 & 99.3 & 48.2 & 46.0 & 11.9 & 8.3 \\
\hline Ile & 149.1 & 151.1 & 71.3 & 78.5 & 46.2 & 63.3 \\
\hline Leu & 251.7 & 269.2 & 113.4 & 125.2 & 46.9 & 99.1 \\
\hline Tyr & 89.7 & 91.2 & 64.8 & 75.1 & 6.8 & 14.5 \\
\hline Phe & 151.6 & 155.3 & 81.4 & 89.2 & 16.4 & 66 \\
\hline Orn & 241.9 & 249.2 & 139.2 & 167.1 & 28.9 & 94.7 \\
\hline Lys & 3310.3 & 3360.4 & 1911.5 & 2511.2 & 302.7 & 505.6 \\
\hline His & 527.7 & 545.2 & 219.6 & 277.3 & 45.8 & 142.5 \\
\hline Cys & 786.9 & 815.1 & 311.7 & 404.8 & 139.1 & 573.2 \\
\hline Arg & 3301.2 & 3313.8 & 1911.1 & 2010.5 & 280.7 & 819.8 \\
\hline Pro & 231.1 & 224.6 & 72.4 & 69.9 & 19.9 & 15.3 \\
\hline
\end{tabular}

stress. Therefore, the ATR system may have been maintained in $L$. lactis exposed to pre-cold stress [14]. These results suggest that exposure to cold, lactic acid, and salt conditions diminish the stress tolerance and survival of $L$. lactis under various stress treatments. Significant physiological responses were also induced in response to pre-adaptation, which in turn, protected cells from the adverse effects of further exposure to high-acid conditions.

Pre-adaptation potentially induced the activation of cysteine-, phenylalanine-, glutamate- and arginine-dependent metabolic pathways to maintain intracellular $\mathrm{pH}$ homeostasis. Thus, preadaptation to cold stress led to the activation of specific metabolic pathways to protect the bacteria from the adverse effects of high-acid conditions and associated secondary effects [1518]. These results suggest that pre-cold stress may activate intracellular metabolic pathways that enhance stress tolerance and survival of $L$. lactis subjected to subsequent acid stress.

As evidenced by Larsen et al, there is a metabolic link between amino acid metabolic pathways and tricarboxylic acid (TCA) cycle [16], via which NADH and succinate are generated. In this study, acid stress exposure caused a decrease in the $\mathrm{NAD}^{+} / \mathrm{NADH}$ ratio. However, preadaptation to cold stress before acid stress exposure increased this ratio and the formation of $\mathrm{OH} \cdot$, which protected the bacteria from secondary oxidative damage induced by acid exposure $[16,19,20]$. These results indicate that pre-cold stress directly or indirectly affected the intracellular amino acid content in a pHdependent manner. Furthermore, pre-cold stress played an important role in intracellular amino acid homeostasis as an adaptive response to lactic acid stress during fermentation.

Metabolic ETC complexes were regulated by different mechanisms in response to preadaptation to cold stress and acid stress exposure. Acid stress generally induces the formation of the NADH dehydrogenase complex. Previous studies have shown that metabolic efflux involved in ETC complexes is regulated in L. lactis that is pre-adapted to cold stress and subsequently exposed to acid stress. This indicates there are differences in $\mathrm{NADH}$ consumption and conversion to $\mathrm{NAD}^{+}$in the ETC in response to stressors [21-24], which can be induced by amino acid homeostasis and redox mobility.

\section{CONCLUSION}

L. lactis maintains a high level of metabolic efficiency when pre-adapted to cold stress before acid exposure. It also maintains maximum redox balance and amino acid haemostasis when $\mathrm{pH}$ is decreased to 3.5. As a result, disruption of redox balance weakens the ability of bacteria to tolerate acid stress. These results also demonstrate that pre-adaptation to cold stress regulates the ATR system in $L$. lactis, resulting in higher viability and acid tolerance in industrial fermentation conditions. 


\section{DECLARATIONS}

\section{Acknowledgement}

This work was supported by National High Technology Research and Development Program of China (863 Program, no. 2011AA100901), Major State Basic Research Development Program of China (973 Program, no. 2013 CB733902), Natural Science Foundation of Jiangsu Province (no. BK2012553) and the National Key Technology R\&D Program of China (no. 2011BAK10B03).

\section{Conflict of Interest}

No conflict of interest associated with this work.

\section{Contribution of Authors}

The authors declare that this work was done by the authors named in this article and all liabilities pertaining to claims relating to the content of this article will be borne by them.

\section{Open Access}

This is an Open Access article that uses a funding model which does not charge readers or their institutions for access and distributed under the terms of the Creative Commons Attribution License (http://creativecommons.org/licenses/by/ 4.0) and the Budapest Open Access Initiative (http://www.budapestopenaccessinitiative.org/rea d), which permit unrestricted use, distribution, and reproduction in any medium, provided the original work is properly credited.

\section{REFERENCES}

1. Louesdon S, Charlot-Rouge $S$, Tourdot-Marechal $R$, Bouix M, Beal C. Membrane fatty acid composition and fluidity are involved in the resistance to freezing of Lactobacillus buchneri R1102 and Bifidobacterium longum R0175. Microb Biotechnol 2015; 8(2): 311-318.

2. Wang YB. Prebiotics: Present and future in food science and technology. Food Res Int 2009; 42(1): 8-12.

3. Tymczyszyn EE, Sosa N, Gerbino E, Hugo A, GomezZavaglia A, Schebor $C$. Effect of physical properties on the stability of Lactobacillus bulgaricus in a freeze-dried galacto-oligosaccharides matrix. Int J Food Microbiol 2012; 155(3): 217-221.

4. Smith WM, Pham TH, Lei L, Dou JC, Soomro AH, Beatson SA, Dykes GA, Turner MS. Heat resistance and salt hypersensitivity in Lactococcus lactis due to spontaneous mutation of IImg_1816 (gdpp) induced by high-temperature growth. Appl Environ Microbiol 2012; 78(21): 7753-7759.
5. Wang $Y$, Delettre J, Corrieu G, Beal C. Starvation Induces Physiological Changes That Act on the Cryotolerance of Lactobacillus Acidophilus RD758. Biotechnol Prog 2011; 27(2): 342-350.

6. Adamberg K, Seiman A, Vilu R. Increased Biomass Yield of Lactococcus lactis by Reduced Overconsumption of Amino Acids and Increased Catalytic Activities of Enzymes. PLoS One 2012; 7(10): 14.

7. Wouters JA, Kamphuis HH, Hugenholtz J, Kuipers OP, De Vos WM, Abee T. Changes in glycolytic activity of Lactococcus lactis induced by low temperature. Appl Environ Microbiol 2000; 66(9): 3686-3691.

8. Jiang RR, Bommarius AS. Hydrogen peroxide-producing NADH oxidase (nox-1) from Lactococcus lactis. Tetrahedron: Asymmetry 2004; 15(18): 2939-2944.

9. Jeanson $S$, Hilgert $N$, Coquillard $M O$, Seukpanya $C$, Faiveley $M$, Neveu $P$, Abraham C, Georgescu $V$, Fourcassie $P$, Beuvier E. Milk acidification by Lactococcus lactis is improved by decreasing the level of dissolved oxygen rather than decreasing redox potential in the milk prior to inoculation. Int $\mathrm{J}$ Food Microbiol 2009; 131(1): 75-81.

10. Walter J, Chagnaud P, Tannock GW, Loach DM, Dal Bello F, Jenkinson HF, Hammes WP, Hertel C. A highmolecular-mass surface protein (Lsp) and methionine sulfoxide reductase $B$ (MsrB) contribute to the ecological performance of Lactobacillus reuteri in the murine gut. Appl Environ Microbiol 2005; 71(2): 979-986.

11. Sporty J, Kabir MM, Turteltaub K, Ognibene T, Lin S, Bench G. Single sample extraction and HPLC processing for quantification of NAD and NADH levels in Saccharomyces cerevisiae. Seperat Sci 2008; 31: 1-30.

12. Mols M, van Kranenburg R, van Melis CCJ, Moezelaar R, Abee T. Analysis of acid-stressed Bacillus cereus reveals a major oxidative response and inactivationassociated radical formation. Environ Microbiol 2010; 12(4):873-885.

13. Kohanski MA, Dwyer DJ, Hayete B, Lawrence $C A$, Collins JJ. A common mechanism of cellular death induced by bactericidal antibiotics. Cell 2007; 130(5): 797-810.

14. Zuljan FA, Repizo GD, Alarcon SH, Magni C. alphaAcetolactate synthase of Lactococcus lactis contributes to $\mathrm{pH}$ homeostasis in acid stress conditions. Int J Food Microbiol 2014; 188: 99-107.

15. Ho CH, Stanton-Cook M, Beatson SA, Bansal N, Turner MS. Stability of active prophages in industrial Lactococcus lactis strains in the presence of heat, acid, osmotic, oxidative and antibiotic stressors. Int $J$ Food Microbiol 2016; 220: 26-32.

16. Larsen N, Moslehi-Jenabian S, Werner BB, Jensen ML, Garrigues $C$, Vogensen FK, Jespersen L. Transcriptome analysis of Lactococcus lactis subsp lactis during milk acidification as affected by dissolved oxygen and the redox potential. Int J Food Microbiol 2016; 226: 5-12.

17. Lee K. Cold shock response in Lactococcus lactis ssp diacetylactis: a comparison of the protection generated 
by brief pre-treatment at less severe temperatures. Process Biochem 2004; 39(12): 2233-2239.

18. Dianawati D, Mishra V, Shah NP. Effect of drying methods of microencapsulated Lactobacillus acidophilus and Lactococcus lactis ssp cremoris on secondary protein structure and glass transition temperature as studied by Fourier transform infrared and differential scanning calorimetry. J Dairy Sci 2013; 96(3): 14191430.

19. Flasarova $R$, Pachlova V, Bunkova L, Mensikova A, Georgova N, Drab V, Bunka F. Biogenic amine production by Lactococcus lactis subsp cremoris strains in the model system of Dutch-type cheese. Food Chem 2016; 194: 68-75.

20. Kaur M, Jayaraman G. Hyaluronan production and molecular weight is enhanced in pathway-engineered strains of lactate dehydrogenase-deficient Lactococcus lactis. Metab, Engi Commun 2016; 3: 15-23.

21. Zhao R, Zheng S, Duan CC, Liu F, Yang LJ, Huo GC. $N A D$-dependent lactate dehydrogenase catalyses the first step in respiratory utilization of lactate by Lactococcus lactis. FEBS Open Bio 2013; 3: 379-386.

22. Imlay JA. Iron-sulphur clusters and the problem with oxygen. Mol Microbiol 2006; 59(4): 1073-1082.

23. Santos AL, Gomes NCM, Henriques I, Almeida A, Correia $A$, Cunha $A$. Contribution of reactive oxygen species to UV-B-induced damage in bacteria. $J$ Photochem Photobiol B-Biol 2012; 117: 40-46.

24. Sudar M, Findrik Z, Domanovac MV, Vasic-Racki D. Coenzyme regeneration catalyzed by $\mathrm{NADH}$ oxidase from Lactococcus lactis. Biochem Eng J 2014; 88: 1218. 